\title{
Correspondence
}

\section{Sexual abuse in children}

Sir,

For many years the nature of my outpatient clinical caseload has necessitated careful inspection of the anus and genitalia in some three quarters of new attenders and many of those recalled for review. Am I now to believe, following the claim in the article by Drs Hobbs and Wynne that up to one in three children are sexually abused, ${ }^{1}$ making it some five times as common as urinary tract infection, and that I have missed several cases a year?

These authors, as well as Dr Leventhal and colleagues, ${ }^{2}$ imply that abuse needs to be suspected in children complaining of enuresis, vaginal discharge, and abdominal pain. These are common organic symptoms in childhood and only occasionally have a psychosomatic basis. Most daytime wetting in girls is due to the urge syndrome; sitting in damp pants causes non-specific vulvitis, with or without discharge, and ammoniacal dermatitis of the labial skin that sometimes extends to the perianal region. The associated pain or itching, or both, may lead to scratching and to digital manipulation of the introitus by the child herself. How may this affect the appearance of the vulva and hymenal diameter? Vaginal sleeve swabs almost invariably grow commensals and, in 22 years' paediatric practice I have only once cultured a sexually transmitted organism; this was in an adolescent girl who admitted having intercourse voluntarily, outside her family circle.

Most girls with urge incontinence have disguised constipation, the clue to which is a firmly palpable descending colon: they sometimes also complain of recurrent abdominal pain, centrally or in the left flank. Dietary enquiry often reveals fibre deficiency, and correction not only eliminates the abdominal pain but also improves the wetting. ${ }^{3}$ Observations on these girls has led me to recognise that most children of either sex complaining of recurrent abdominal pain have a similar problem of dietary fibre deficiency and are not emotionally disturbed. The passage of large, hard stools undoubtedly inflicts damage on the anus, as recently reported. ${ }^{4}$ The anal reflex, elicited routinely to test the integrity of sacral innervation in incontinent children, requires that a relaxed anus contracts in response to stimulating the perianal skin. How easy it would be for the inexperienced to interpret the preliminary relaxation as 'reflex dilatation' and the reflex contraction as 'twitchiness.'

While I do not doubt the existence of sexual abuse, or the sincerity of Drs Hobbs and Wynne, I am disturbed by the distortion of perspectives which their article creates. In the real world, parents need to have confidence that the paediatrician to whom they take their child for advice can be trusted to deal sympathetically with their symptoms, be they enuresis or abdominal pain, and not subject them to an inquisition with sexual abuse uppermost in his or her mind. In their final comments (p 1195) Drs Hobbs and
Wynne imply that the current controversy has polarised paediatricians and police surgeons. If, indeed, it is a contest, I would suggest that it is the police surgeons who are making the paediatricians look foolish!

\section{References}

${ }^{1}$ Hobbs CJ, Wynne JM. Management of sexual abuse. Arch Dis Child 1987;62:1182-7.

2 Leventhal JM, Bentovim A, Elton A, Tranter M, Reed L. What to ask when sexual abuse is suspected. Arch Dis Child 1987;62:1188-93.

${ }^{3}$ White RHR. Management of urinary tract infection. Arch Dis Child 1987;62:421-7.

${ }^{4}$ Sunderland R. Child sexual abuse. Lancet 1987;ii:1018.

R H R WHITE

The Children's Hospital,

Ladywood Middleway,

Birmingham B16 8ET

Sir,

The highly publicised controversy concerning the significance of anal dilatation has produced a series of dogmatic assertions that have already been influential in the collapse of care proceedings in a number of cases. It is high time their logic was challenged.

Dr Raine Roberts, writing in this journal, states that anal dilatation in a 'subjective and misleading test.' 1 Her distrust of anal dilatation seems to be based on two arguments: firstly, she states that she and her colleagues in Manchester, seeing children for police and social services, have found anal signs in only a handful of cases compared with the large numbers described in Leeds. ${ }^{2}$ Dr Wynne supports her cases with photographs and detailed case histories. Surely Dr Roberts is not suggesting that Dr Wynne has fabricated her results? Secondly, she states that anal dilatation "cannot be used in evidence. . . . because it is also present in some children who have not been abused.' She states that dilatation can occur in constipation, threadworm, and anal thrush. She supports this statement with reference to Dr Graham Clayden in a letter to the Lancet. ${ }^{3}$ Dr Clayden's letter makes no mention of thrush or threadworm and simply states his belief, based on experience with a highly specialised clinic population, that chronic constipation can cause anal dilatation. He produces no numerical data, however, and appears to make the assumption that those children manifesting anal dilatation are not silent victims of sexual abuse, without undertaking any investigation or disclosure work.

A multitude of possible causes of -anal dilatation have been named in courts of law and in the media, but in fact no study exists that shows or even suggests the occurrence of anal dilatation in association with such conditions as thrush, threadworm, diarrhoea, or indeed, constipation. Moreover all these speculated causes are commonplace in 